\title{
Assessment of the Right-to-Try Law: The Pros and the Cons
}

\author{
Brandon Brown ${ }^{1}$, Camerin Ortiz ${ }^{2}$, and Karine Dubé ${ }^{3}$ \\ ${ }^{I}$ Center for Healthy Communities, Department of Social Medicine, Population, and Public Health, University of California Riverside \\ School of Medicine, Riverside, California; ${ }^{2}$ Syracuse University, Department of Biology, Syracuse, New York; and ${ }^{3}$ University of \\ North Carolina Gillings School of Global Public Health, Chapel Hill, North Carolina
}

O

n May 30, 2018, the Right-To-Try bill, allowing the use of experimental, non-Food and Drug Administration (FDA)approved drugs as a last resort for those unable to participate in clinical testing who have also exhausted all other treatment options, was signed into law (1). At the time this bill was signed, 38 states had passed similar Right-To-Try laws; this law is nationwide (1). The requirements for granting approval of experimental drug treatment under Right-To-Try laws are: (1) a terminally ill patient has exhausted all other treatment options and is ineligible to participate in clinical trials, (2) the experimental drug passes FDA phase 1 clinical testing, (3) the patients' health-care provider or treating physician must recommend and approve the experimental treatment, (4) the pharmaceutical manufacturer must approve the drug for use as an experimental treatment, and (5) patients' written informed consent is required $(2,3)$. Although certain experimental drugs may improve some patients' conditions, adverse health effects or no health improvement are more likely.

In the following text we weigh the pros and cons of the federal Right-To-Try law.

\section{CONS}

\section{Limited Patient Understanding}

One requirement before beginning experimental drug therapy is patient informed consent. Consent documents are often confusing, written in a way that is difficult to understand, and contain highly technical terms at great length, which can result in patients missing or misunderstanding the gist of the experiment $(4,5)$. Similarly, there may be misunderstanding of experimental drugs and their likely success rates, as well as the potential of therapeutic misconception (b). Terminally ill patients who feel as if they are running out of time may be swayed by the false hope provided by an experimental procedure, which can outweigh potentially detrimental effects of the experimental drug and other unintended consequences.

\section{Lowered Trust in the FDA}

The FDA's clinical trial and review process took more than $50 \mathrm{y}$ to establish in order to ensure that pharmaceuticals are safe for their intended use (7). Although this highly regulated process can require up to $15 \mathrm{y}$ for a drug to receive FDA approval, it is an effective method that weeds out most ineffective or dangerous

Received Jul. 11, 2018; revision accepted Jul. 18, 2018.

For correspondence or reprints contact: Brandon Brown, University of California Riverside, Center for Healthy Communities, 3333 14th St., Riverside, CA 92508.

E-mail: Brandon.brown@ucr.edu

Published online Aug. 10, 2018.

COPYRIGHT ( 2018 by the Society of Nuclear Medicine and Molecular Imaging. DOI: 10.2967/jnumed.118.216945 drugs (8). Arguably, Right-To-Try laws are hypocritical because they rely on the FDA process of determining the toxicity and possible side effects of products in phase 1 testing, but this argument ignores the fact that drugs need to be rigorously tested to be deemed safe for widespread use (3). There is a need to protect patients' trust in the clinical research enterprise.

\section{Financial Consequences}

Marginalized patients could be vulnerable to exploitation through Right-To-Try. The legislation does not contain incentives for insurance companies to cover experimental treatment costs and the potential outcomes of the treatment $(2,9)$. Insurance companies in many states that passed Right-To-Try laws have denied hospice coverage, home health-care coverage, and even health-care coverage for at least 6 mo after treatment $(2,9)$. This denial of coverage creates a financial burden left for the families, who often cannot pay.

\section{Decreased Liability}

One of the most problematic issues with the federal Right-ToTry legislation is provided immunity from liability for physicians and pharmaceutical companies $(2,4)$. Without FDA oversight, pharmaceutical companies can push unsafe drugs on sick patients. Although it is presumed that primary care physicians have their patients' best interest in mind, physicians can own pharmaceutical company stock and charge patient treatment fees (2). Pharmaceutical companies, for their part, need have no fear that any negative outcomes from experimental drugs will hurt the chances of the drug becoming FDA approved, as this legislation prohibits the FDA from including negative outcomes of experimental treatments in the data that are used to approve the pharmaceuticals $(2,10)$. Lack of systematic reporting of adverse events may result in decreased information for the public and providers.

\section{Safety Consequences}

Nearly $70 \%$ of drugs pass phase I testing (11). However, most drugs that pass phase I will be deemed unsafe or ineffective, failing to pass subsequent stages (11). There is a low probability that experimental drugs tested in early-stage research will significantly benefit patients and a higher probability that side effects from experimental interventions could worsen their condition $(2,12)$. Additionally, the FDA expanded access process has been revised to be more transparent and to take less time: patients can now complete the expanded access request form within an hour (13). Right-To-Try legislation has helped make undertested drugs more readily accessible by reducing FDA oversight, which was created to protect patients and consumers from unsafe pharmaceuticals. Another consideration is the growing epidemic of counterfeit medicine; another reason to protect the integrity and safety of the drug development process (14). 


\section{PROS}

\section{Experimental Drugs May Extend Life}

In most cases, experimental treatments have not yet proven effective. However, they can potentially extend life (15). Compassionate use has been used in epidemics with a high death rate (e.g., the Ebola outbreak in 2013-2016) $(16,17)$. Widely untested therapeutic vaccines were given to people living with Ebola in hopes of improving their condition (18). Given a setting of compassionate use, even unsuccessful treatment may help strengthen patients' trust in health-care systems due to potentially positive health outcomes.

\section{In Line with Expanded Access}

The case for the terminally ill to try potential life-extending drugs has been addressed by the FDA $(8,13)$. Dr. Scott Gottlieb, Commissioner of the FDA (May 2017-present), has stated that the FDA approves almost all expanded access requests: high urgency immediately or over the phone, and all other requests within a few days (13). The Right-To-Try legislation is very similar to the Expanded Access program in that it recognizes that a streamlined process is necessary if experimental drugs are to reach patients who may not have any other options.

\section{Gives Patients More Options}

Supporters of the Right-To-Try law argue that the law will not replace Expanded Access but will create another avenue to streamline the process for experimental treatments (3). Although the FDA receives around 1,000 requests annually for experimental drug therapies, many such therapies never make it to the FDA $(12,13)$. Confusing online forms and multiple attachments can be barriers to getting experimental drugs approved for use, and by that point of approval patients' conditions may have worsened significantly. Right-To-Try laws are intended to further streamline this process, allowing patients to work directly with doctors to acquire nonclinically tested drugs, bypassing the FDA and providing multiple options for all terminally ill patients to acquire potentially life-extending drugs. The federal Right-To-Try law intends to give people more control over their life/health. Even if experimental treatments are ineffective, the argument is that people should have a choice to at least try a drug that may produce medical benefits. Similarly, medical aid in dying allows patients to make important medical decisions toward the end of their life (10). Some argue that if patients have the right to end their life with medical aid in dying, they should also have the right to try to extend their lives with experimental drugs (19). Personal choice over what happens to one's health near the end of life is aligned with the ethical principle of autonomy and can be empowering.

\section{FINAL THOUGHTS}

One of the main principles the Right-To-Try law was built on ways to reduce pain and suffering. However, bypassing FDA regulations means the data that would normally be available for physicians and clinical researchers, such as dosage, drug administration, and side effects, will be limited. The potential for lowered trust in the clinical research enterprise, financial and safety consequences, decreased liability, and limited patient understanding clearly outweigh the potential benefits of the experimental drugs tested outside the FDA purview.

That being said, health-care systems are often paternalistic and may treat the disease rather than the patient. Academics are similar in how they choose research projects and participants. For patients to make a well-informed decision, they must be provided good, clear knowledge regarding the benefits and limitations of experimental treatments (19). These patients also must have enough information to assess the risks of these treatments, including full comprehension of the severity of possible side effects as well as financial costs. In complicated clinical research, proper explanation and understanding of these issues may take several pages of text, and key points may get lost in the shuffle. However, the autonomy of those at the end of life should be respected, and terminally ill individuals should be given the opportunity make well informed decisions. This is why we side with the patient to have more options via Right-To-Try.

\section{DISCLOSURE}

No potential conflict of interest relevant to this article was reported.

\section{ACKNOWLEDGMENT}

We thank Jo Gerrard for editorial support.

\section{REFERENCES}

1. Dyer O. Trump signs bill to give patients right to try drugs. BMJ. 2018:361:k2429.

2. Bateman-House A, Robertson CT. The federal right to try act of 2017: a wrong turn for access to investigational drugs and the path forward. JAMA Intern Med. 2018; 178:321-322.

3. Carrieri D, Peccatori FA, Boniolo G. The ethical plausibility of the 'Right To Try' laws. Crit Rev Oncol Hematol. 2018;122:64-71.

4. Hoerger M. Right-to-try laws and individual patient "compassionate use" of experimental oncology medications: a call for improved provider-patient communication. Death Stud. 2016;40:113-120.

5. Nijhawan LP, Janodia MD, Muddukrishna BS, et al. Informed consent: issues and challenges. J Adv Pharm Technol Res. 2013;4:134-140.

6. Christopher PP, Appelbaum PS, Truong D, Albert K, Maranda L, Lidz C. Reducing therapeutic misconception: a randomized intervention trial in hypothetical clinical trials. PLoS One. 2017;12:e0184224.

7. Dabrowska A, Thaul S. How FDA approves drugs and regulates their safety and effectiveness. 2018. Federation of American Scientists website. https://fas.org/ sgp/crs/misc/R41983.pdf. Published May 8, 2018. Accessed August 16, 2018.

8. Rubin MJ, Matthews KRW. The impact of Right To Try laws on medical access in the United States. 2016. Baker Institute website. http://bakerinstitute.org/research/right-try-unproven-drugs/. Accessed August 16, 2018.

9. Meyerson D. Medical negligence determinations, the "Right to Try," and expanded access to innovative treatments. J Bioeth Inq. 2017;14:385-400.

10. Joffe S, Lynch H. Federal Right-to-Try legislation: threatening the FDA's public health mission. New Engl J Med. 2018;378:695-697.

11. The drug development process: step 3-clinical research. U.S Food and Drug Administration website. https://www.fda.gov/ForPatients/Approvals/Drugs/ucm405622. htm. Updated January, 4, 2018. Accessed August 16, 2018.

12. Morrison C. Critics say "right to try" wrong for patients. Nat Biotechnol. 2018;36: 294-295.

13. Examining patient access to investigational drugs. Scott Gottlieb, M.D., before the House Subcommittee on Health, Committee on Energy and Commerce Testimony. U.S Food and Drug Administration website. https://www.fda.gov/NewsEvents/ Testimony/ucm578634.htm. Updated on October 3, 2017. Accessed August 16, 2018.

14. Fantasia HC, Vooys KM. Public health implications of counterfeit medications. Nurs Womens Health. 2018;22:264-268.

15. Caplan AL, Bateman-House A. Should patients in need be given access to experimental drugs? Expert Opin Pharmacother. 2015;16:1275-1279.

16. Folayan M, Brown B, Yakubu A, Peterson K, Haire B. Compassionate use of experimental drugs in the Ebola outbreak. Lancet. 2014;384:1843-1844.

17. Calain P. The Ebola clinical trials: a precedent for research ethics in disasters. J Med Ethics. 2018;44:3-8.

18. Rid A, Emanuel EJ. Ethical considerations of experimental interventions in the Ebola outbreak. Lancet. 2014;384:1896-1899.

19. Darrow JJ, Sarpatwari A, Avorn J, Kesselheim AS. Practical, legal, and ethical issues in expanded access to investigational drugs. N Engl J Med. 2015;372:279-286. 